\title{
States of Being: Art and identity in digital space and time
}

\author{
Jonathan P. Bowen \\ London South Bank University \\ School of Engineering \\ London, UK \\ http://www.jpbowen.com \\ jonathan.bowen@lsbu.ac.uk
}

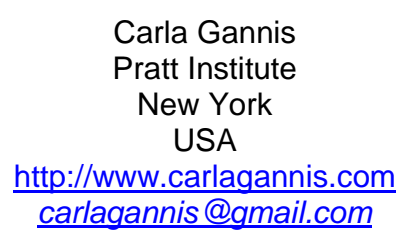

Bruce Wands

MFA Computer Arts

School of Visual Arts

New York, USA

http://www.brucewands.com

bwands@sva.edu

\author{
Tula Giannini \\ Pratt Institute \\ School of Information \\ New York, USA \\ http://mysite.pratt.edu/ giannini/ \\ giannini@pratt.edu
}

\author{
Jeremy Gardiner \\ Ravensbourne \\ London \\ UK \\ http://www.jeremygardiner.co.uk \\ j.gardiner@rave.ac.uk
}

\author{
Gareth Polmeer \\ Royal College of Art \\ London \\ UK \\ http://www.garethpolmeer.com \\ gareth.polmeer@network.rca.ac.uk
}

\author{
Jonathan Kearney \\ University of the Arts London \\ Camberwell College of Arts \\ London, UK \\ http://www.jonathankearney.com \\ j.kearney@arts.ac.uk
}

\begin{abstract}
This one-day Symposium explored themes of personhood, modernity and digital art, bringing together speakers from a range of disciplines to consider technology, artistic practice and society. It seeks a renewed consideration of the role of art in illuminating human identity in a positive relation with technology, and its transformative effects upon space and time. The concerns for the role of art amidst the forces of a post-modern world are influenced by important legacies of the past, by which ideas about human identity and difference have been made meaningful in the relation of history and technology. In the frequently transient and conflicting forces of humanness and forces of modernity, the digital world of the arts emerges as a means by which new ideas of space and time can be considered, with new perspectives of human identity seen as states of being, towards the possibilities of experience, technology, individuality and society.
\end{abstract}

Digital art. Digital culture. Digital humanities. Digital identity. Digitalism.

\section{INTRODUCTION}

This day-long Symposium of invited talks on the first day of the EVA London 2018 Conference follows on from the previous two EVA London Pre-conference Symposiums held in 2016 and 2017 (Bowen \& Giannini 2016; Bowen, Giannini \& Polmeer 2017). The Symposium started in association with the Pratt Institute London Sumer School, with an emphasis on digital culture and heritage (Bowen \& Giannini 2014; Giannini \& Bowen 2016). A collaboration with the Royal College of Art developed, providing a philosophical angle to the Symposium (Polmeer
2016). Aspects of digital culture (Giannini \& Bowen 2018; 2019) and art continue in this year's Symposium, which also considers educational issues for digital artists.

The 2018 Symposium covers questions about digital theory and practice in the area of art and identity, from both a historical and contemporary context. Presenters come from a variety of backgrounds, including both artists and academics. The Symposium is rounded off with a panel session at the end of the day. This wide-ranging set of 
presentations is designed to be contrasting as well as thought-provoking. Summaries and backgrounds of talks and speakers are included in the following section.

\section{PROGRAMME}

Carla Gannis, Pratt Institute, New York, USA

\section{Title: An Artist, an Al, and an Alchemist Walk into a Bar..}

This presentation is on the element of humour that has run throughout many avant-garde movements of the $20^{\text {th }}$ century, Dada, Fluxus, the Situationist International, Pop Art and Feminist Art, acting as a voice of opposition to "high art" culture and exclusionary practices in representation. This ties with her own practice, as a digital artist, where she is using comical strategies, in the guise of an artificially intelligent agent, as tactical social critique. The presentation also showcases the work of other contemporary digital artists who have incorporated humour as biting social satire into their practices.

\section{Background}

Carla Gannis is a digital artist who has previously presented at the EVA London 2017 Symposium (Bowen et al. 2017) and Conference (Gannis 2017), where she also exhibited at the associated V\&A Digital Futures evening event (Papadimitriou 2017).

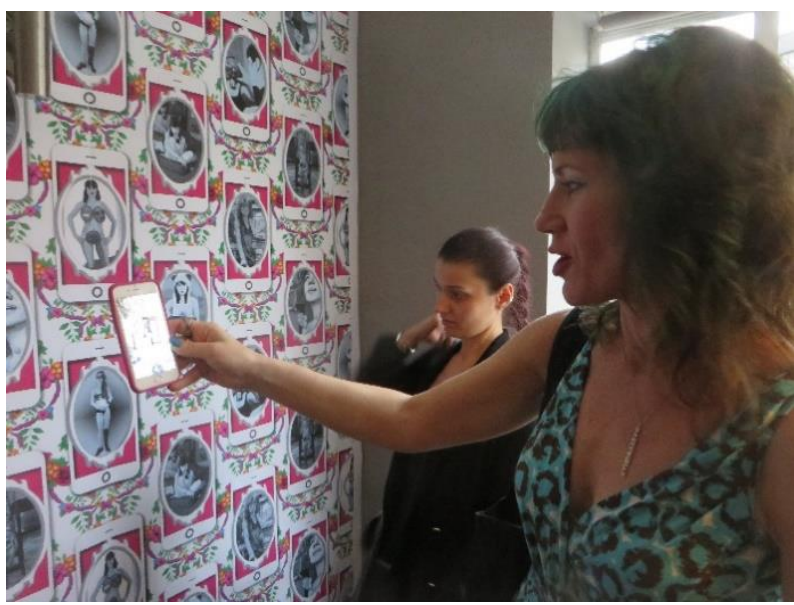

Figure 1: Carla Gannis demonstrating her artwork at the EVA London 2017 Digital Futures exhibition (Gannis 2017; Papadimitriou 2017). (Photograph by Jonathan Bowen.)

Jeremy Gardiner, Ravensbourne, London, UK

\section{Title: The Geometry of the Coast}

My presentation focuses on my deep and long-term interest with the geology of landscape and how it is shaped by the forces of nature. I explore hybrid techniques that combine painting, drawing, immersive virtual reality and additive and subtractive fabrication. I see myself as painter and digital craftsman, experimenting with the cross-fertilisation of old and new technologies to create new forms (Gardiner \& Head 2013; Gardiner 2016). The notion of a single view of landscape is something I seek to dispel. Instead, I consider my images to be like a musical score, composed of themes and variations; a series of views pieced together to create a fragmented multi-layered vision of the coast.

One section might be a view of the landscape seen on a coastal walk, another a cross-section of a fossil found in that location, whilst another element might be the contour patterns seen from the air captured by LiDAR, an optical remote sensing technology that can measure the change in elevation of the landscape using pulses from a laser. I will examine how my working process is influenced by science, geomorphology, new technologies and direct physical engagement with ancient landscapes and how the pictures I make reflect an understanding of different landscapes their underlying structures and unique history.

\section{Biography}

Jeremy Gardiner is a former Harkness Fellow of the Media Lab of the Massachusetts Institute of Technology. $\mathrm{He}$ is a Churchill Fellow and has been awarded a New York Foundation for the Arts fellowship and NESTA grant. His paintings and prints are about spirit and sense of place, particular landscapes, their contours and unique history (Gardiner \& Head 2013; Gardiner 2016). His artwork is held in numerous private and public collection including, BNP Paribas, Glaxo Smith Kline, Ente Nazionale Idrocarburi, Government Art Collection and the V\&A. His most recent exhibition, 'Geology of Landscape', a survey of Painting and prints spanning two decades 1998-2017 was at the Candida Stevens Gallery from $9^{\text {th }}$ June $-7^{\text {th }}$ July 2018.

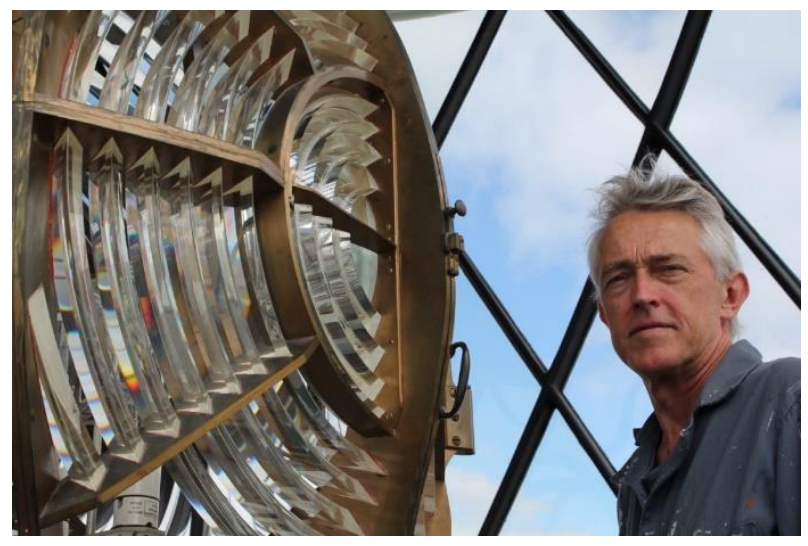

Figure 2: Jeremy Gardiner and the Fresnel Lens at Start Point Lighthouse. 


\section{Jonathan Weinel, Aalborg University, Denmark}

\section{Title: Altered States of Consciousness in Electronic Music and Audio-Visual Media}

The concept of altered states of consciousness informs a range of contemporary artistic practices, from modern psychedelic art and music to 'cyberdelic' virtual reality applications (Weinel 2018a, 2018b, 2018e). Yet the imperative of creating work to represent or induce changes in perception is ancient, with some theorists arguing that the earliest cave paintings represent hallucinatory visions.

Building on an interest in this topic spanning almost 20 years, which includes a PhD in creative practice composing music and audio-visual art (Weinel 2018d), Jon Weinel's recent book Inner Sound: Altered States of Consciousness in Electronic Music and Audio-Visual Media (Weinel 2018c) is a trek across the creative influence of altered states on music and art. From Amazonian chicha festivals to the synaesthetic assaults of neon raves in Denmark and Croatia; and from an immersive outdoor electroacoustic performance on an Athenian hilltop to a mushroom trip on a tropical island in virtual reality, Weinel ultimately presents a new theory for considering altered states in relation to the design of electronic music and audio-visual media.

At the EVA London 2018 Symposium, Jon Weinel introduces some of the key themes of Inner Sound. It is also notable in this context that the book discusses issues of design and perception that are highly relevant for a range of contemporary practices in immersive media and digital arts, including various work that will be showcased by others during this year's conference.

Jonathan Kearney, Camberwell College of Art, London, UK

\section{Title: Art Practice and Learning in Digital Time and Space: A dialogue of withness}

Digital time and space often carries with it the metaphors of the massive, the rhizomic, endless intertwined connections.

Drawing on diverse influences from evolutionary biology, learning theories and theology, this paper will explore these metaphors in the context of online art learning and making.

Since 2004 at Camberwell College of Arts, part of the University of the Arts London, we have delivered a small but highly effective fine art practice based masters course (Kearney 2018) with half the students physically based in London and half fully online living anywhere in the world. Drawing on this experience of fine art blended learning and art making, I present ongoing areas of research.

Rather than exploring from the position of certainty, this paper will speculate and raise several questions using the diverse influences already mentioned. Starting with an exploration of interactions between evolutionary biologist Robin Dunbar's suggestion that 150 is the theoretical cognitive limit to social relationships and George Siemens learning theory of connectivism, which promotes the idea of socially distributed knowledge and learning. This raises questions about digital space and time and whether the massive scale needs to be reconsidered.

I suggest that a theological idea of 'being with' might allow a more nuanced and positively ambiguous concept to explore learning and making. A dialogue of 'withness', both between learners and materials, suggests the potential to hold together both the minute scale of the individual and the massive potential of the rhizomic network.

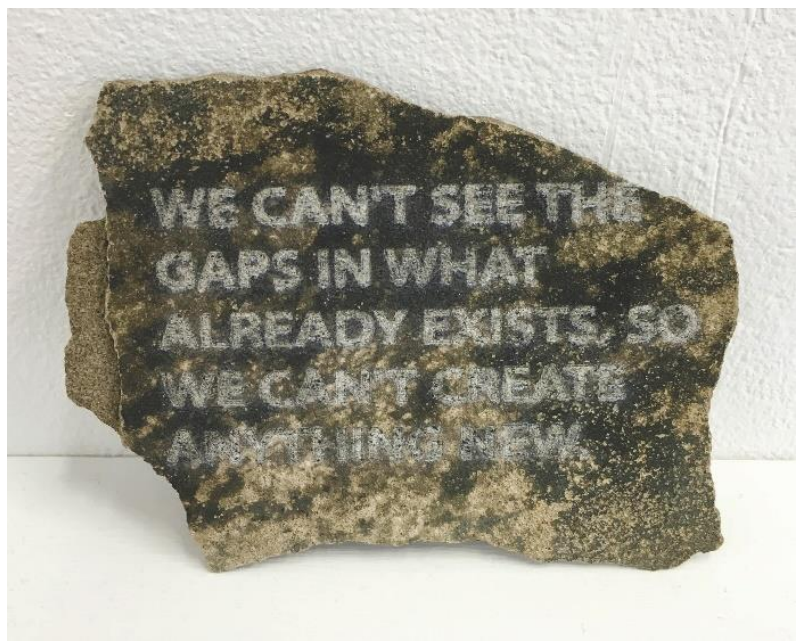

Figure 3: Detail of 'dérives' (2017) by Trystan Williams, an MA Fine Art Digital graduate at the Camberwell College of Arts, London.

\section{Biography}

Jonathan Kearney is a British artist, Course Leader for MA Fine Art Digital and Postgraduate Programme Director at the University of the Arts London (UAL) Camberwell College of Arts (Kearney 2018). Since 2004, he has pioneered online learning for fine art masters students, uniquely MA Fine Art Digital is offered both as a studio based course in London and as a fully Online option. Research interests; online and blended pedagogy; art practice and theology engagement; fine art practice in a digital environment. 
Bruce Wands, School of Visual Arts, New York, USA

\section{Title: A Portrait of the Artist in the Digital Age}

While the classic portrait of an artist in the garret is centuries old and still relevant, contemporary artists are establishing new identities using digital tools and media for creating, experiencing, exhibiting and disseminating their creative work. While the digital revolution in art spans several decades, artists have been working with technology since the early $20^{\text {th }}$ century with the emergence of the Futurism, Dada and Avant-garde, Fluxus in the 1960s and 1970s.

While digital art cannot be specifically described as an art movement with philosophical underpinnings, the emergence of making art with technology and redefining the traditional media of drawing, painting and sculpture spawned an interest in what the digital could add to creative self-expression. The pioneers of digital art relied on limited access to computers, partnerships between artists and computer scientists and programming. There are two main pathways of digital art: evolutionary and revolutionary. Evolutionary digital art includes media such as photography and video and revolutionary changes enable artists to make creative work that was not possible before new technology was invented. Two examples of creative work by the author will illustrate these changes.

The first example is an interactive music installation titled Variations. It incorporated DVD-Audio technology, which was invented in 2000. DVD-Audio enabled the playback of full spectrum high-quality audio on six channels, as opposed to 5.1 surround sound, which was a theatrical and video format. By composing music in six channels and playing it back through an interactive interface consisting of tubes and balls, participants could move the balls on and off the tubes and create their own mix of the music. The work was exhibited in the SIGGRAPH Art Gallery, Millennium Museum in Beijing, Belgium, and the UK. Like many technologies, DVD-Audio became obsolete in 2007 and the specialised DVD players used for it are now difficult to locate. DVD surround sound has now become the de facto standard.

Another example is the Buddha Paintings created by the author. Tibetan thangka paintings date back thousands of years and are secular Buddhist Art. By using the underlying geometry upon which the thangkas are based, abstract images using volumetric light created in the software MAYA were created. In doing so, the secular nature of the imagery was transformed into imagery which is accessible to international audiences.
These two examples illustrate is how digital art has expanded the creative options available to the contemporary artist. While it is beyond the scope of this presentation to explore all the evolutionary and revolutionary changes made to art making, the Internet contains hundreds of websites of digital artists.

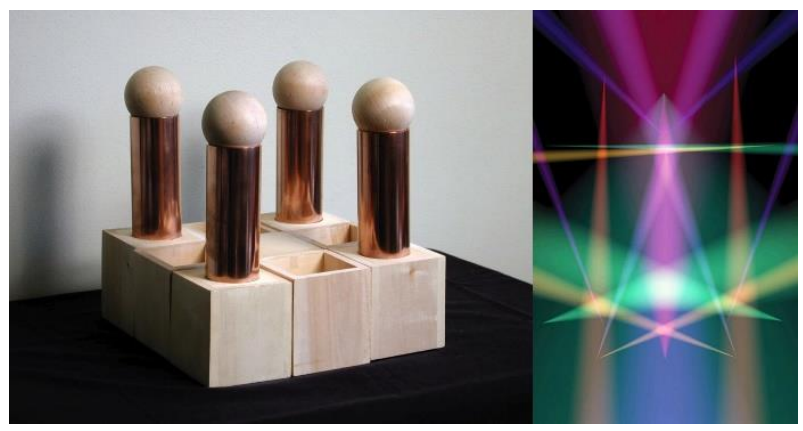

Figure 4: The left image is the "Variations" interface exhibited in the First Beijing International New Media Arts

Exhibition, 2004. The right image is the "Buddha Light

Painting" in the Art in the Digital Era exhibition in Guangzhou, China, 2010.

(Images Copyright (C) Bruce Wands.)

\section{Biography}

Bruce Wands has been working in digital media and music for more than forty years as an artist, writer and musician. His creative work explores the relationship between digital art, mathematics, new forms of narrative, sound art, music and the creation of contemporary American folk art. Exhibitions and lectures include the First Beijing International New Media Arts Exhibition; Decoding the Digital Conference, Victoria and Albert Museum; Electronics Alive, Florida; and the SIGGRAPH Conference and Art Gallery. His books are Art of the Digital Age (Wands 2006) and Digital Creativity by (Wands 2002). Bruce Wands is Chair Emeritus of the MFA Computer Art Department, Founder of the BFA Computer Art Department and the Director of Computer Education at the School of Visual Arts in New York City. He has been awarded grants from the NEA, Rockefeller Foundation, and NYSCA. He has also presented papers at the main EVA London conference (Wands 2017; Wands 2018).

\section{Tula Giannini, Pratt Institute, New York, USA}

\section{Title: Creating Art and Identity on the Internet: Digital Reality and States of Being}

As life increasingly plays out on the Internet, human states of being, both conscious and unconscious are recast in digital incarnations of self and identity. The Internet, and especially the web as a global creative platform and public space of communication and interaction brings together and juxtaposes diverse identities, places and spaces that more than ever, cause us question who we are in real and virtual life as we seek to evolve towards an integrated self that 
is at once physical and digital. This paper considers the impact of these changes in what is often described as a paradigm shift by which human existence is becoming part of today's digital ecosystem in which life itself is encoded and integral to the Internet of Life (loL) - of sorts. How is this emerging state of living on the Internet changing art and culture? As we enter the next wave of the digital revolution marked by the digital convergence of all media, we explore these questions from diverse perspectives, which seem to indicate that we have reached a digital point of no return. There's no going back to pre-digital life, the question is who will we be in our digital future.

\section{States of digital being and art on the Internet} The future is now (Amerika 1997):

"GRAMMATRON, a futuristic create in "a public domain narrative environment" .... depicts a nearfuture world where stories are no longer conceived for book production but are instead created for a more immersive networkednarrative environment that, taking place on the Net, calls into question how a narrative is composed, published and distributed in the age of digital dissemination."

Looking back to 1997, eight years after Tim BernersLee invented the World Wide Web, Mark Amerika created the groundbreaking work, GRAMMATRON, introducing the notion of "The Virtual Artist in Cyberspace" foreshadowing $21^{\text {st }}$ century developments that today have made the Internet a central platform for seeing, creating and communicating art. The exhibition, "Art in the Age of the Internet, 1989 to Today," which opened on 7 February 2018 at the Institute of Contemporary Art (ICA) in Boston, USA, is one of the first major exhibitions to focus on the revolutionary changes to the theory and production of art brought about by the web (ICA 2018). According to the show's curator, Eva Respini, "It's a show about how the internet has affected art" (Sayel 2018), noting that (Respini (2017):

\section{"The internet has introduced a new way of seeing and being - It's affected how we shop, eat, date, travel, our social behaviors, our political machines, and how we create and consider art."}

The show is organised around several themes including new ways of thinking about the human body and its enhancement, how the Internet is being used for surveillance and social causes, access to information and images, virtual communities, virtual worlds, social media and performing the self. The latter theme delves into how we create and perceive our digital selves in art and on the web as the selfie takes centre stage in terms of the relationship between art and identity.

The Whitney Museum of American Art in New York also took up the surveillance theme which was featured in the 2016 exhibition, "Astro Noise" by Laura Poitras. The show, which used the entire 8th floor of the museum, was narrated through the artist's personal archive of film, video and FBI documents which conveyed her experiences in Russia where she interviewed and filmed Edward Snowden in Russia, and victims of the Iraq War to convey her story of being constantly under surveillance by the FBI. This brings to light social contexts of contemporary culture and constructs of gender identity.

The Internet as a creative platform for reimagining art and the artist

The Met Museum's Open Access Initiative makes some 350,000 works of art from its collections available online adding substantially to the vast art collections on the web being used to support scholarship and creative endeavours while inspiring art works to be reimagined. For example, Simone Seagle, a web and educational software developer, has used this open access collection to create several animations of master paintings that literally breathe new life into how we view these works. Seagle's animated GIFs of Kandinsky's Violett, Claude Monet's Bridge Over a Pond of Lilies, 1889, and Ōide Tōkō's Cat Watching a Spider, c.1888-92 can viewed on the Met Museum's website (Seagle 2018).

Large-scale digitisation of art works is making possible the use and reuse of works in ways not before imagined. Although we have no way of knowing how these artists would view their works reimagined as animated GIFs, this would seem beside the point, which is to encourage new ways of looking at earlier works, through the use of new digital technologies, thanks to open access museum initiatives like that at the Met Museum.

\section{Life through the digital lens (by T. Giannini)}

$$
\begin{aligned}
& \text { Who am I online } \\
& \text { In digital space and time } \\
& \text { Feeling free } \\
& \text { of reality } \\
& \text { Looking into the lens } \\
& \text { Click } \\
& \text { My digital self appears } \\
& \text { Sharing myself with friends } \\
& \text { press send } \\
& \text { entering the digital ecosphere }
\end{aligned}
$$

\section{Background}

Tula Giannini is a professor and former Dean of the School of Information at the Pratt Institute, New York. She has previously presented at the EVA London 2017 Conference (Giannini 2013; Bowen \& Giannini 2014; Giannini \& Bowen 2015; 2016; 2017) and co-chaired the previous EVA London Symposia (Bowen \& Giannini 2016; Bowen, Giannini \& Polmeer 2017). She is the lead editor of a 
forthcoming book on Museums and Digital Culture (Giannini \& Bowen 2018; 2019).

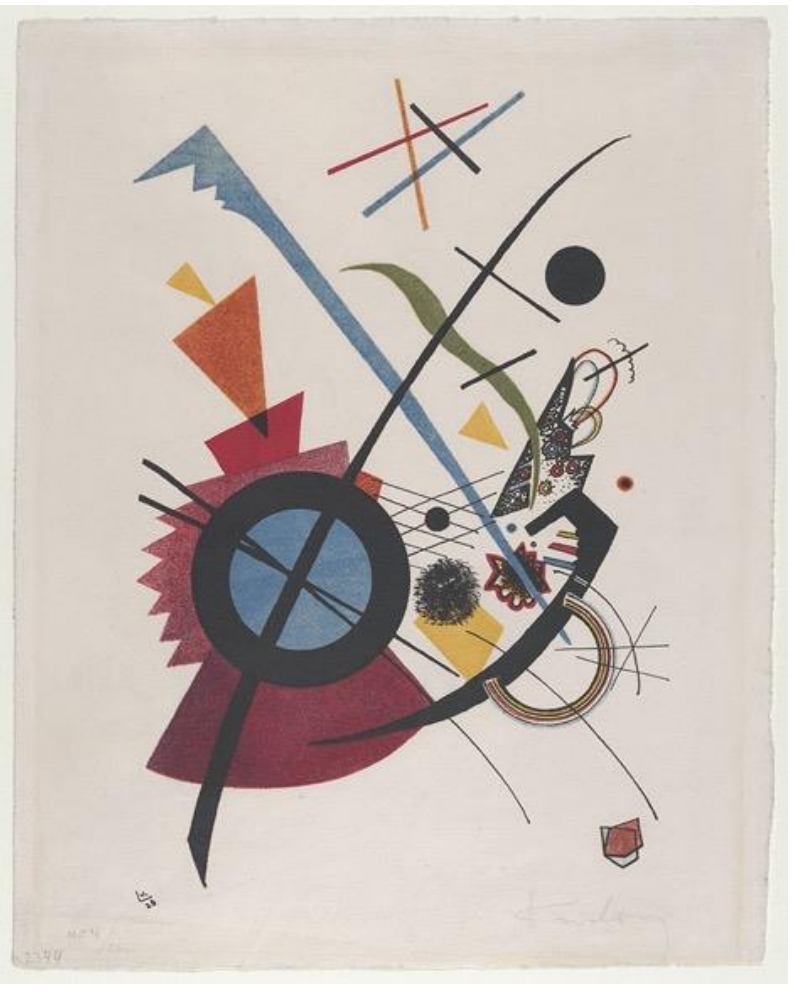

Figure 5: "Vasily Kandinsky (French [born Russia], 1866-1944). Violett, 1923. Lithograph in red, yellow, blue, and black, $117 / 16 \times 7 / 12 \mathrm{in}$. $(29.1 \times 19.1 \mathrm{~cm})$. The Metropolitan Museum of Art, New York, Bequest of Blance Risa Sussman, 1991 (1991.1066.1)" (Quoted from Met Museum website.)

\section{PANEL SESSION}

All speakers contributed to a panel session, chaired by Carla Gannis, at the end of the Symposium. The session was an opportunity for speakers to comment on other presentations and well as for the audience to raise more general questions.

\section{CONCLUSION}

The Symposium talks have been designed to cover a wide range of issues in digital theory and practice, in the context of art, culture, and humanities, especially with respect to identity. A bibliography of related publications by the Symposium chairs and speakers is included below for further reading.

It is interesting to note that the co-chairs of this Symposium (Jonathan Bowen, Tula Giannini, and Gareth Polmeer) are from the School of Engineering, School of Information, and formerly School of Humanities, at their respective institutions. This reflects the interdisciplinary nature of the topic covered by the Symposium. An aim of all the authors and presenters is to help break down these barriers and synergistically benefit from the wide range of experiences of all those involved in the Symposium.

Online information concerning the EVA London 2018 Symposium is available under:

http://www.eva-london.org/eva-london2018/symposium/

Acknowledgements

The EVA London 2018 Symposium was generously supported by the School of Information, Pratt Institute, New York. Jonathan Bowen is grateful to Museophile Limited for financial support.

\section{REFERENCES}

Amerika, M. (1997.) GRAMMATRON.

http://www.grammatron.com/about.html (retrieved 9 May 2018).

Bowen, J. P., Diprose, G., and Lambert, N. (eds.) (2016) EVA London 2016: Electronic Visualisation and the Arts. BCS, Electronic Workshops in Computing. $\quad$ http://www.bcs.org/ewic/eva2016 (retrieved 9 May 2018).

Bowen, J. P., Diprose, G., and Lambert, N. (eds.) (2017) EVA London 2017: Electronic Visualisation and the Arts. BCS, Electronic Workshops in Computing. http://www.bcs.org/ewic/eva2017 (retrieved 9 May 2018)

Bowen, J. P. and Giannini, T. (2014) Digitalism: The new realism? In K. Ng, J. P. Bowen, \& S. McDaid (eds.), EVA London 2014: Electronic Visualisation and the Arts. BCS, Electronic Workshops in Computing, pp. 324-331. DOI:

10.14236/ewic/eva2014.38

Bowen, J. P. and Giannini, T. (2016) From analogue to digital in literature and art. In Bowen et al. (2016), pp. 1-4. DOI: $\underline{10.14236 / \text { ewic/EVA2016.1 }}$

Bowen, J. P., Giannini, T., and Polmeer, G. (2017) Coded communication: Digital senses and aesthetics, merging art and life. In Bowen et al. (2017), pp. 1-8. DOI: $10.14236 /$ ewic/EVA2017.1

Bowen, J. P., Keene, S., and Ng, K. (eds.) (2013) Electronic Visualisation in Arts and Culture. Springer, Series on Cultural Computing.

Bowen, J. P., Weinel, J., Diprose, G., and Lambert, N. (eds.) (2018) EVA London 2018: Electronic Visualisation and the Arts. BCS, Electronic Workshops in Computing. (This volume.) http://www.bcs.org/ewic/eva2018

Gannis, C. (2017) The augmented selfie. In Bowen et al. (2017), pp 319-326. DOI:

10.14236/ewic/EVA2017.66 
Gardiner, J. and Head, A. (2013) Light years: Jurassic Coast: An immersive 3D landscape project. In Bowen et al. (2013), Chapter 6, pp. 75-89. DOI: 10.1007/978-1-4471-5406-8 6

Gardiner, J. (2016) 3D LIDAR Rapid prototype relief model of the Jurassic Coast. In Bowen et al. (2016), pp. 289-290. DOI:

10.14236/ewic/EVA2016.59

Giannini, T. (2013) Visualizing Brooklyn: The Brooklyn Visual Heritage website. In K. Ng, J. P. Bowen, \& S. McDaid (eds.), EVA London 2013: Electronic Visualisation and the Arts. BCS, Electronic Workshops in Computing, pp. 9-16. https://ewic.bcs.org/content/ConWebDoc/50974 (retrieved 15 May 2018).

Giannini, T. and Bowen, J. P. (2015) Galois connections: Mathematics, art, and archives. In $\mathrm{K}$. $\mathrm{Ng}$, J. P. Bowen, \& N. Lambert (eds.), EVA London 2015: Electronic Visualisation and the Arts. BCS, Electronic Workshops in Computing, pp. 176-191. DOI: $\underline{10.14236 / \text { ewic/eva2015.18 }}$

Giannini, T. and Bowen, J. P. (2016) Curating digital life and culture: Art and information. In Bowen et al. (2016), pp. 237-244. DOI:

10.14236/ewic/EVA2016.46

Giannini, T. and Bowen, J. P. (2017) Life in code and digits: When Shannon met Turing. In Bowen et al. (2017), pp. 51-58. DOI: 10.14236/ewic/EVA2017.9

Giannini, T. and Bowen, J. P. (2018) Of museums and digital culture: A landscape view. In Bowen et al. (2018). (This volume.)

Giannini, T. and Bowen, J. P. (eds.) (2019) Museums and Digital Culture: New Perspectives and Research. Springer, Series on Cultural Computing. (To appear.)

ICA (2018) Art in The Age of The Internet, 1989 to Today. The Institute of Contemporary Art, Boston, USA. https://www.icaboston.org/exhibitions/artage-internet-1989-today (retrieved 9 May 2018).

Kearney, J. (2018) Jonathan Kearney - MA Fine Art Digital Course Leader. Camberwell College of Arts, University of the Arts London, UK.

http://www.arts.ac.uk/camberwell/people/postgradu ate-staff/jonathan-kearney/ (retrieved 10 May 2018).

Papadimitriou, I., Addis, J., Lomas, A., Dekker, L., Singporewala, K., and Tresset, P. (2017) Digital Futures: Lumen Big Reveal. In Bowen et al. (2017), pp. 438-440. DOI: 10.14236/ewic/EVA2017.86
Polmeer, G. (2016) Sublating time: Hegel's speculative philosophy and digital aesthetics. In Bowen et al. (2016), pp. 257-264. DOI: 10.14236/ewic/EVA2016.49

Respini, E. (2017) On the Internet: A Q+A with Eva Respini. The Institute of Contemporary Art, Boston, USA, 17 November.

https://www.icaboston.org/articles/internet-qa-evarespini (retrieved 9 May 2018).

Sayel, S. (2018) Creativity in the digital age: how has the internet affected the art world? The Guardian, 2 February.

https://www.theguardian.com/artanddesign/2018/fe b/02/art-in-the-age-of-the-internet-exhibition-boston

Seagle, S. (2018) Open Access at The Met: Animating artworks in the collection. Metropolitan Museum of Art, New York, USA, 30 January. https://www.metmuseum.org/blogs/collectioninsights/2018/open-access-artwork-animations (retrieved 14 May).

Wands, B. (2002) Digital Creativity. John Wiley \& Sons.

Wands, B. (2006) Art of the Digital Age. Thames \& Hudson.

Wands, B. (2017) The engagement of digital art with contemporary art. In Bowen et al. (2017), pp. 340344. DOI: $\underline{10.14236 / \text { ewic/EVA2017.69 }}$

Wands, B. (2018) 25 years of curating digital art 1993-2018. In Bowen et al. (2018). (This volume.)

Weinel, J. (2018a) Finding 'the weird' in psychedelic art, OUPblog, Oxford University Press, 18 January. https://blog.oup.com/2018/01/finding-weirdpsychedelic-art/ (retrieved 3 April 2018).

Weinel, J. (2018b) Getting high on virtual reality, OUPblog, Oxford University Press, 4 January. https://blog.oup.com/2018/01/getting-high-virtualreality/ (retrieved 3 April 2018).

Weinel, J. (2018c) Inner Sound: Altered States of Consciousness in Electronic Music and AudioVisual Media. New York: Oxford University Press.

Weinel, J. (2018d) Jon Weinel [online portfolio]. http://www.jonweinel.com (retrieved 3 April 2018).

Weinel, J. (2018e) Ten virtual reality games that simulate altered states, OUPblog, Oxford University Press, 13 March.

https://blog.oup.com/2018/03/virtual-reality-gamessimulate-altered-states/ (retrieved 3 April 2018). 